\title{
A fabricação da excelência na escola pública: notas acerca de práticas educacionais e trajetórias escolares de sucesso
}

* Lisandra Ogg Gomes

\begin{abstract}
RESUMO
Este trabalho tem como principal propósito conhecer e analisar as condutas e as trajetórias escolares de alunas e alunos que frequentam a última série do ensino médio do Colégio de Aplicação da Universidade Federal de Viçosa (CAP/COLUNI/UFV), bem como as características dessa instituição de ensino que se notabiliza, no país, pela excelência do ensino que oferece. Trata-se de parte de uma investigação que abrange a tríade alunos/alunas de sucesso, escola pública de excelência e famílias, cujo pressuposto é o de que a constituição de um processo de excelência escolar depende de uma diversidade de fatores. A metodologia de pesquisa conciliou procedimentos quantitativos e qualitativos, em particular os depoimentos obtidos em entrevistas realizadas com o corpo discente. Os primeiros resultados mostraram que o exame de seleção, as práticas pedagógicas, a formação de professores e a mobilização dos/as estudantes são algumas das variáveis que configuram a excelếncia nessa escola pública.
\end{abstract}

Palavras-chave: Sociologia da Educação. Ensino Médio. Sucesso escolar.

\begin{abstract}
In this socio-theoretical study, our main purpose is to understand the educational trajectories of male and female high performance students in the last term of high school at Colégio de Aplicação da Universidade Federal de Viçosa (CAP/COLUNI/UFV), and also the actions and characteristics of efficiency and excellence employed by this institution. Therefore, our research encompasses the triad of successful students, the public school of excellence and the families, because, with good reason, we understand that variety factors. The metodology rely on proceeding quantitative and qualitative, especially for this article, the analysis of sociocultural data and grades in interviews conducted with students of this institution. The first results showed that the selection exam, teaching practices, teacher training and students mobilization contributes for to academic success.
\end{abstract}

Keywords: Education Sociology. High School. Academic Success.

$\mathrm{N}$ o cenário atual da escola pública brasileira, a preocupação com a qualidade do ensino e com o desempenho dos estudantes coloca em evidência tanto a eficiência das instituições de ensino como o rendimento dos jovens estudantes. Considerando que o Brasil conta com duas grandes redes de ensino que recrutam públicos diferentes, que no interior da rede pública de ensino também existem diferenciações segundo o regime administrativo (federal, estadual, municipal), identificar e conhecer as 
características das instituições públicas consideradas de excelência e as características de sua clientela pode fornecer subsídios indiretos para a formulação de políticas educacionais que levem à melhoria desse serviço público no país. Neste texto apresentaremos os primeiros resultados da pesquisa $A$ construção da excelência escolar: itinerários, trajetórias e práticas de sucesso de alunos de uma escola pública brasileira de prestígio do ensino médio, atualmente em andamento no quadro de um estágio pós-doutoral realizado no OSFE/ PPG em Ed. da Universidade Federal de Minas Gerais (UFMG) ${ }^{1}$. Trata-se, em particular, de um estudo sociológico a respeito das práticas empregadas por um colégio público de excelência do ensino médio e das disposições e condutas de seus alunos e suas alunas, bem como de suas famílias.

A instituição de realização da pesquisa é o Colégio de Aplicação da Universidade Federal de Viçosa (CAP/COLUNI/UFV) e os alunos e as alunas investigados frequentam a $3^{\text {a }}$ série do ensino médio. A escolha dessa instituição deve-se a sua trajetória contínua de sucesso nos rankings do Exame Nacionais de Ensino Médio (ENEM). Desde o início dos anos 2000, os estudantes dessa instituição têm conquistado um alto desempenho tanto no ENEM, quanto em vestibulares altamente seletivos. No caso do ENEM, nos últimos sete anos o CAP/COLUNI desponta entre as dez escolas melhores colocadas e como a primeira dentre as públicas nacionais (NOGUEIRA; LACERDA, 2014), o que resultou na construção do alto prestígio dessa instituição e daqueles que a frequentam.

Sabemos que diferentes fatores - culturais, sociais e econômicos - têm impacto na construção da excelência escolar, mas a forma como estão arranjados, evidenciada a partir das práticas e dos discursos dos educadores, dos estudantes e de suas famílias, é o que nos interessa conhecer. Seus sentidos constituirão o foco da análise no decorrer deste texto, a partir dos dados coletados. Primeiramente trataremos da especificidade dos colégios federais e do CAP/COLUNI no cenário educacional. Em seguida, abordaremos tanto a excelência da instituição, quanto de seu alunado.

O CAP/COLUNI no cenário educacional

Um aspecto singular do sistema educacional brasileiro é a sua atuação desigual e as complexas divisões hierárquicas dentro desse
1 Agradeço o apoio do Consetho Nacional de Desenvolvimento Científico e Tecnológico (CNPq) para realização dessa pesquisa (processo 164094/2013-0) que deu origem a este artigo. 
sistema. 0 ensino médio é um retrato dessa complexidade, pois ele ainda não foi capaz de universalizar sua cobertura, apresenta altos índices de reprovação e de evasão, além da falta de consenso sobre os princípios que deveriam nortear seu currículo e a formação - humanista ou profissional que oferece. Além disso, é forte no imaginário da nação a ideia de que a boa qualidade do ensino médio está associada à rede privada, ocultando o fato de que no interior da rede pública de ensino subsiste uma segmentação responsável pela diversificação em seus padrões de qualidade.

Defato, noBrasil,essenível deensinoéoferecidoporestabelecimentos privados e públicos, sendo esses últimos majoritariamente estaduais, ainda residualmente municipais ${ }^{2}$, e excepcionalmente militares e federais ${ }^{3}$, como, por exemplo, os colégios de aplicação das grandes universidades, os institutos federais, escolas e centros técnicos e agrotécnicos.

Especificamente, os colégios de aplicação foram criados no governo de Eurico Gaspar Dutra (1946-1951), a partir do Decreto-Lei nº 9.053 de 12 de março de 1946 (BRASIL, 1946). Segundo essa lei, as Faculdades de Filosofia, Ciências e Letras federais teriam a obrigação de "manter um ginásio de aplicação destinado à prática docente dos alunos matriculados nos cursos de Didática" (BRASIL, 1946). Atualmente, os colégios de aplicação continuam vinculados às universidades federais, são regidos pelas mesmas diretrizes universitárias e devem contemplar as atividades de ensino, pesquisa e extensão.

Mas antes de se tornar colégio de aplicação, o CAP/Coluni fora criado como colégio universitário. Esse modelo de instituição surgiu a partir da Lei de Diretrizes e Bases da Educação de 1961 (Lei nº. 4.024) que previa, em seu capítulo II, artigo 79 , parágrafo $3^{\circ}$, que a universidade poderia instituir "colégios universitários" destinados a ministrar o ensino da terceira série do ciclo colegial (antigo ensino médio). Do mesmo modo que poderia instituir colégios técnicos universitários quando nela existisse curso superior em que sejam desenvolvidos os mesmos estudos. Nos concursos de habilitação ao ensino superior não se faria qualquer distinção entre candidatos que tenham cursado esses colégios e os que provenham de outros estabelecimentos de ensino médio (BRASIL, 1961).

Foi nesse contexto que a Universidade Rural de Minas Gerais (UREMG, de 1949 até sua federalização em 1969) - atual Universidade Federal de Viçosa (UFV) - implantou o COLUNI em 26 de março de $1965^{4}$. O colégio nasceu para atender a uma demanda da universidade, como sugere o primeiro regimento do COLUNI, de 1966, em que se registrava
2 A Lei $n^{\circ}$. 11.494, de 20 de junho de 2007, estabelece que os Estados receberão os recursos do Fundo de Manutenção e Desenvolvimento da Educação Básicas (FUNDEB) com base nos alunos matriculados no ensino fundamental e médio. Por sua vez, os Municípios receberão o FUNDEB com base no número de alunos da educação infantil e ensino fundamental.

3 Segundo os dados Censo da educação básica de 2012 (INSTITUTO NACIONAL DE ESTUDOS E PESQUISAS EDUCACIONAIS ANÍSIO TEIXEIRA, 2013, p. 24), no Brasil a “[...] rede estadual continua a ser a maior responsável pela oferta de ensino médio, com $85 \%$ das matrículas. A rede privada atende $12,7 \%$ e as redes federal e municipal atendem juntas pouco mais que $2 \%$ ". 
que a nova instituição destinava-se à preparação e formação da "elite" de jovens que posteriormente ingressariam nos cursos de graduação da UFV. Essa ideia se manteve com a aprovação do segundo regimento, no ano de 1971.

Além de consagrar a complementação do ensino de nível médio como objetivo fundamental do COLUNI, como previsto na LDB No. 4.024, o 'Novo' Regimento deixa explícita uma função de 'nivelamento', entre os dois níveis de ensino (Médio e Superior), destacando ser este uma espécie de 'primeiro ciclo, com fins de recuperação das insuficiências evidenciadas pelo concurso vestibular'. (BARBALHO, 2008, p. 50). Destaque do autor.

De 1965 até 1981, o colégio ofertava apenas a última série do ensino médio - funcionando como um curso pré-vestibular. De 1982 a 1994, ocorreu a institucionalização e implantação da primeira e segunda séries, e de 1994 a 2005 ocorreu o processo de transformação do então Colégio Universitário (COLUNI) para Colégio de Aplicação (CAP) (BARBALHO, 2008, p. 18), engendrando a nova denominação de CAP/COLUNI.

Tanto Barbalho (2008) como Nogueira e Lacerda (2014) sublinham que, desde sua criação, o CAP/COLUNI teve como objetivo preparar jovens para o ingresso na Universidade, com um trabalho orientado para a formação humanista e científica. Mesmo quando da Lei $n^{\circ}$. 5.692/71, que fixava um caráter profissionalizante para o ensino médio, o colégio driblou essa exigência da legislação incluindo na grade curricular a disciplina de Desenho Técnico Arquitetônico, apenas em caráter de urgência, para validar os certificados de conclusão dos alunos nesse nível de ensino (BARBALHO, 2008).

Ao longo do tempo, o CAP/COLUNI foi forjando seu alto conceito no âmbito da formação de nível médio, o qual é continuamente alimentado pela aprovação de seus egressos em processos seletivos de instituições superiores de prestígio e em cursos que formam para as carreiras mais valorizadas (NOGUEIRA; LACERDA, 2014). Os dados abaixo divulgados no Jornal da UFV e no trabalho de Nogueira e Lacerda (2014) - Tabela 1 e 2 - confirmam esses altos índices de aprovação dos estudantes em diferentes vestibulares e a posição do colégio nas classificações feitas do ENEM, sendo que essa tendência tende a se ampliar com as mudanças que vêm ocorrendo no processo de entrada nas universidades públicas, em particular com o Sistema de Seleção Unificado (SISU). Através desses sistemas foram extintos os vestibulares em sua forma tradicional e as 
instituições de ensino superior oferecem vagas para candidatos a partir da nota obtida no ENEM.

Tabela 1: Porcentagem de aprovação em exame vestibulares dos egressos do CAP/COLUNI/UFV - 2005/2009

\begin{tabular}{c|c|c|c|c}
\hline Turma & $\begin{array}{c}\text { Ano do } \\
\text { Vestibular }\end{array}$ & $\begin{array}{c}\text { Aúmero total } \\
\text { de formados }\end{array}$ & $\begin{array}{c}\text { Número de } \\
\text { aprovados no } \\
\text { vestibular }\end{array}$ & $\begin{array}{c}\text { Aproveitamento } \\
\text { no vestibular }\end{array}$ \\
\hline 2005 & 2006 & 159 & 123 & $77,3 \%$ \\
2006 & 2007 & 144 & 116 & $80,5 \%$ \\
2007 & 2008 & 156 & 117 & $75 \%$ \\
2008 & 2009 & 152 & 118 & $77,6 \%$ \\
2009 & 2010 & 147 & 126 & $85,7 \%$ \\
\hline
\end{tabular}

Fonte: Jornal da UFV. Edição Especial, ano 37, 26 de março de 2010, Viçosa.

Tabela 2: Posição do CAP/COLUNI nas classificações de estabelecimentos públicos e privados, em nível nacional - 2006/2012

\begin{tabular}{c|c|c}
\hline $\begin{array}{c}\text { Ano de realização } \\
\text { do ENEM }\end{array}$ & $\begin{array}{c}\text { Posição na } \\
\text { classificação dos } \\
\text { estabelecimentos } \\
\text { públicos }\end{array}$ & $\begin{array}{c}\text { Posição na classificação dos } \\
\text { estabelecimentos públicos } \\
\text { e privados }\end{array}$ \\
\hline 2006 & $1^{\circ}$ lugar & $7^{\circ}$ lugar \\
2007 & $2^{\circ}$ lugar & $9^{\circ}$ lugar \\
2008 & $1^{\circ}$ lugar & $3^{\circ}$ lugar \\
2009 & $1^{\circ}$ lugar & $5^{\circ}$ lugar \\
2010 & $1^{\circ}$ lugar & $9^{\circ}$ lugar \\
2011 & $1^{\circ}$ lugar & $8^{\circ}$ lugar \\
2012 & $1^{\circ}$ lugar & $7^{\circ}$ lugar \\
\hline
\end{tabular}

Fonte: citado em NOGUEIRA; LACERDA, 2014, p. 138.

A admissão no CAP/COLUNI se dá por meio de um exame anual de seleção que é realizado em duas etapas:

A primeira se constitui de uma prova de múltipla escolha, de caráter eliminatório, cuja pontuação máxima é 68 pontos. Na segunda etapa, é feita a prova discursiva e a redação, com o valor total de 32 pontos. De acordo com a nota obtida na primeira fase, os candidatos são classificados até um total de três candidatos por vaga, o que pode ser ultrapassado caso ocorra empate na pontuação dos últimos classificados na primeira fase. A classificação final é feita considerando a soma da pontuação obtida nas duas fases do processo seletivo. A partir de 2010 , o colégio passou a adotar uma política de 
ação afirmativa que consiste na concessão de um bônus de 15\% sobre a pontuação final, para os candidatos que cursaram todo o ensino fundamental em escola pública (NOGUEIRA; LACERDA, 2014, p. 143, grifo nosso).

Todos os anos, o colégio oferece 150 vagas para o ingresso na $1^{\text {a }}$ série e não aceita matrículas na $2^{\mathrm{a}}$ e $3^{\mathrm{a}}$ séries, a não ser que existam vagas ociosas, as quais são preenchidas a partir de uma nova prova de seleção. Essas vagas ociosas devem-se majoritariamente ao fato de que, segundo $o$ regimento do colégio, o aluno tem direito a apenas uma reprovação, caso contrário perde o direito à matrícula, ou seja, "é jubilado", no linguajar dos alunos.

Por fazer parte da UFV e ter sede própria dentro de seu campus, os alunos do CAP/COLUNI têm acesso à Biblioteca Central, Praça de Esportes, Divisão de Saúde e ao Restaurante Universitário ${ }^{5}$. 0 prédio do colégio tem uma arquitetura moderna e conta com salas de aula, laboratórios de química, física e biologia, salas de projeção, sala de informática com acesso à internet, gabinetes para os professores e salas para os gestores e a administração. Segundo a opinião dos alunos, um ponto positivo do colégio é a sua aparência:

\footnotetext{
- Ah, eu acho que esteticamente o colégio é bem bonito... $\mathrm{E}$, tipo assim, todo mundo que vem (aqui) fica impressionado com a beleza e isso acaba motivando sempre a querer ficar aqui, a amar o colégio e a gostar bastante do colégio (luri, 17 anos, $3^{\mathrm{a}}$ série).

- Quando cheguei aqui, achei (o colégio) de outro mundo, sabe, e disse: quero estudar aqui! (Lucas, 17 anos, $3^{\mathrm{a}}$ série) ${ }^{6}$
}

No ano de 2014, o CAP/COLUNI contava com um total 480 alunos, distribuídos em 12 turmas abrangendo as três séries, e com aproximadamente 40 alunos por turma. Diariamente os alunos têm seis aulas de 50 minutos e um intervalo de 20 minutos no meio do período. As $1^{\text {as }}$ séries têm aulas no período vespertino, iniciando às 13 horas e terminando às $18 \mathrm{~h} 20^{7}$. As $2^{\text {as }}$ e $3^{\text {as }}$ séries frequentam o colégio no período matutino e suas atividades começam às 7 horas e terminam às $12 \mathrm{~h} 20$. De todo modo, a circulação dos alunos nos dois períodos é constante, pois no contra turno podem estudar nas dependências da instituição, e recorrer aos professores para esclarecimento de dúvidas ou encontros de pesquisa.

Os projetos científicos e as atividades culturais desenvolvidos pelo CAP/COLUNI são diversos e diversificados, a saber:
5 Apenas a moradia estudantil não lhes é disponibilizada.

6 Os nomes dos entrevistados são fictícios a fim de preservar sua identidade.

7 Às sextas-feiras as atividades do período vespertino são encerradas às $17 \mathrm{~h} 30$. 
a) Programa Institucional de Bolsas de Iniciação Científica para o Ensino Médio (PIBIC-EM) que consiste em pesquisas acadêmicas realizadas em parceria e com orientação de um professor da UFV;

b) ProjetoAstronomia, baseado em atividades, palestras e participação nas Olímpiadas de Física;

c) Química Forense, que consiste na utilização e aplicação de conhecimentos de química a problemas de ordem judicial, trabalhista, industrial, ambiental etc.;

d) Quinta Cultural e o Compondo o Palco constituído por apresentações artísticas preparadas pelos alunos;

e) Cuidar do lugar, com ações educativas voltadas para a preservação do espaço, patrimônio e segurança da escola;

f) atividades esportivas, como torneios, jogos escolares etc ${ }^{8}$.

Além dessas, outras atividades extraclasses fazem parte da agenda do colégio por iniciativa dos próprios alunos, e contam com o apoio da escola. Durante as entrevistas pudemos notar o quanto elas são valorizadas por professores e alunos, os quais consideram que elas ampliam a formação acadêmica e, como dizem, faz parte de uma "formação para a vida". Dentre elas, encontram-se:

a) o MINIONU (Modelo Intercolegial das Nações Unidas), um projeto promovido pelo Departamento de Relações Exteriores da PUC Minas, que possui alunos e alunas coordenadores em cada escola, com a proposta de debater temas internacionais";

b) o Cursinho Popular Pré-Coluni criado e mantido pelos alunos do $3^{\circ}$ ano, consistindo em aulas que preparam estudantes do último ano do ensino fundamental público para o exame de seleção do Coluni;

c) a revista eletrônica $O$ Prisma que está em sua $3^{a}$ edição e trata de temas contemporâneos diversos ${ }^{10}$

d) o Cine Coluni que exibe filmes escolhidos pelos estudantes seguidos de debates.

O corpo docente conta atualmente com 41 professores (35 efetivos e 6 substitutos), todos contratados por meio de concurso público. Seu regime de trabalho é o de dedicação exclusiva ou 40 horas semanais, obedecendo as mesmas normas que regem o sistema federal de ensino superior. Desses, 23 professores são egressos da Universidade Federal
8 COLÉGIO DE APLICAÇÃO DA UNIVERSIDADE FEDERAL DE VIÇOSA, 2014.

9 PONTIFÍCIA UNIVERSIDADE CATÓLICA DE MINAS GERAIS, 2014.

10 Mais sobre a revista, cf. http://issuu.com/oprismacoluni 
de Viçosa e quatro deles são ex-alunos do próprio COLUNI. A formação docente é um dos pontos positivos do colégio mais apontado e valorizado nas entrevistas com os discentes, em especial pela alta titulação do professorado. A tabela 3 abaixo traz a distribuição dos docentes segundo sua titulação máxima.

Tabela 3: Percentual de titulação acadêmica do corpo docente efetivo ano 2014

\begin{tabular}{c|c|c}
\hline Titulação & Números de professores & $\%$ \\
\hline Pós-doutorado & 01 & 2,85 \\
Doutorado & 14 & 40 \\
Mestrado & 14 & 40 \\
Especialização & 3 & 8,6 \\
Graduação & 1 & 2,85 \\
Sem informação & 2 & 5,7 \\
Total & 35 & 100 \\
\hline
\end{tabular}

Fonte: Pesquisa realizada na página da internet do CAP/COLUNI e na Plataforma Lattes do CNPq.

Caracterização da pesquisa e dos/as participantes

Os sujeitos da pesquisa são os professores, os gestores, as famílias e, principalmente, os alunos e as alunas da terceira série do ensino médio do CAP/COLUNI. Considerando o total de 160 alunos que, no segundo semestre de 2014, estavam matriculados nessa série, selecionamos uma amostra de 40 estudantes terceiranistas, segundo o critério do desempenho escolar (nota geral), tal como indicado pela equipe de coordenação e orientação educacional. 0 resultado foi a constituição de três grupos: alunos/as com aproveitamento escolar "elevado", "baixo" e "dentro da média ${ }^{11 "}$.

A escolha do último período do ensino médio foi em razão desses estudantes terem uma trajetória contínua nesse estabelecimento, vivenciando de forma direta e intensa as normas, regras, expectativas e as práticas pedagógicas daí decorrentes. Além disso, também nos interessa conhecer suas trajetórias acadêmicas após a saída dessa instituição.

O principal instrumento de pesquisa utilizado foi a entrevista semiestruturada com estudantes e pais de alunos, gestores e professores, além do grupo focal com os alunos. A entrevista com os estudantes abrangeu

11 De acordo com o Regimento do colégio (UUNIVERSIDADE FEDERAL DE VIÇOSA, 2003), artigo 71 , é considerado aprovado o aluno que alcançar aproveitamento escolar igual ou superior a 60 pontos. Além disso, o artigo 66 estabelece que o sistema de avaliação do rendimento escolar será bimestral, com valores de $20,25,25$ e 30 pontos. 
questões acerca da estrutura e do nível socioeconômico e sociocultural de suas famílias, de sua própria trajetória escolar, de suas práticas cotidianas, em particular, suas práticas de estudo. Mas procedemos também à observação de aulas (de Física, Filosofia e Literatura), de conselho de classe (do $3^{\circ}$ bimestre), de discussões dos alunos sobre o projeto político pedagógico ${ }^{12}$, além de conversas informais com professores nos momentos de intervalo.

Além disso, nos valemos também de fontes secundárias e documentais tais como: o regimento da escola, o questionário sociocultural que ela aplica aos candidatos a ingresso, o Jornal da UFV e a página do CAP/COLUNI na internet.

As características sociais e acadêmicas dos/as alunos/as do CAP/COLUNI

O alunado do CAp/COLUNI é, sem dúvida, diferente daquele das escolas públicas estaduais e municipais. As escolas de ensino médio federais são valorizadas e reconhecidas pela boa qualidade de seu ensino ${ }^{13}$ e, por isso, são atraentes para as famílias muito mobilizadas no que tange à escolarização dos filhos, e mesmo para os próprios jovens, como atesta um dos alunos: “- Normalmente você tem aquela visão de escola pública que não é coisa muito boa, muito didática, e isso aqui ( o CAP/COLUNI) é totalmente diferente, é uma das exceções" (Joaquim, 17 anos, $3^{\text {a }}$ série).

Para afirmar essa diferença, baseamo-nos nos dados do questionário sociocultural aplicado aos candidatos ao ingresso, no ato de sua inscrição ao exame de seleção, nos anos de 2007 a 2011 aos quais tivemos acesso ${ }^{14}$ , considerando apenas os dados daqueles que foram aprovados/as. Esse questionário contem perguntas fechadas sobre as características escolares, sociais, culturais e econômicas do candidato, e sobre sua informação prévia acerca do colégio.

Para nossa análise consideramos as perguntas semelhantes nos dois questionários a partir dos principais categorias sociológicas socioculturais, como, por exemplo, ocupação, renda e sexo. Além disso, priorizamos a análise de questões a respeito do ensino fundamental dos candidatos.

A fim de identificar a ocupação exercida pelos progenitores dos alunos, o questionário da instituição se pauta por uma grade de seis agrupamentos, na qual o agrupamento 1 constitui o mais alto escalão de profissões (ex: banqueiro, grande industrial, grande proprietário rural, alto posto administrativo no serviço público etc.); seguido do
120 projeto político pedagógico está em construção e conta com a participação de discentes, docentes, gestores e funcionários.
13 Esse alto nível de qualidade certamente tem a ver com o fato de estarem vinculadas ao sistema das universidades federais (RESENDE; NOGUEIRA; NOGUEIRA, 2011).
14 De 2007 até 2009, o questionário era composto de 19 perguntas; a partir de 2010 , foram acrescida mais 15 questões contabilizando 34 ao todo. 
agrupamento 2 (profissionais liberais de nível universitário, cargos técnico-científicos, cargos de chefia ou gerência em empresas, entre outros); seguido do agrupamento 3 (bancários, professores primários e secundários, funcionário público de nível médio, pequeno industrial, comerciante médio etc.); seguido do agrupamento 4 (operário qualificado, balconista, recepcionista, motorista, marceneiro e assemelhados); seguido do agrupamento 5 (operário não qualificado, lavrador, servente, biscateiro, faxineira, empregada doméstica, pedreiro etc.); e finalmente o agrupamento 6 constituído apenas pelas donas de casa.

Com base nessa grade, verificou-se que as profissões dos pais dos alunos situam-se majoritariamente nos agrupamentos dois, três e quatro, isto é, entre os setores médios da população - Gráfico 1.

Gráfico 1: Ocupação dos pais dos ingressantes segundo os agrupamentos - 2007/2011

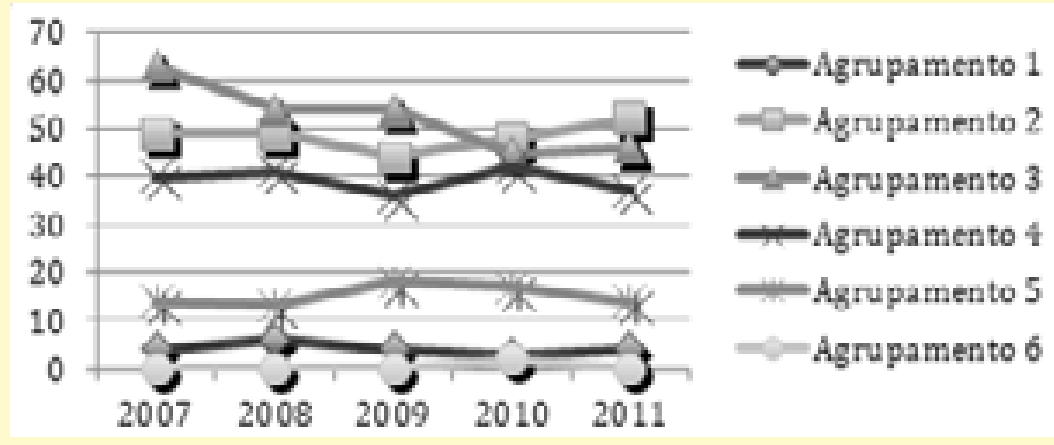

Fonte: Elaborado pela autora.

Porsuavez, as profissões das mãesencontram-se predominantemente no agrupamento três, com alguma aproximação com os agrupamentos dois e seis - Gráfico 2. Ao estudar uma escola federal de nível médio, da cidade de São Paulo, Arco Netto (2011) sustenta que conquanto as mães possuam uma escolarização mais elevada do que a de seus maridos, elas, muitas vezes, sacrificam sua carreira para cuidar dos filhos, e enfrentam a insegurança estrutural no mercado de trabalho, a qual é reforçada pelas desigualdades de gênero. 
Gráfico 2: Ocupação das mães dos ingressantes segundo os agrupamentos - 2007/2011

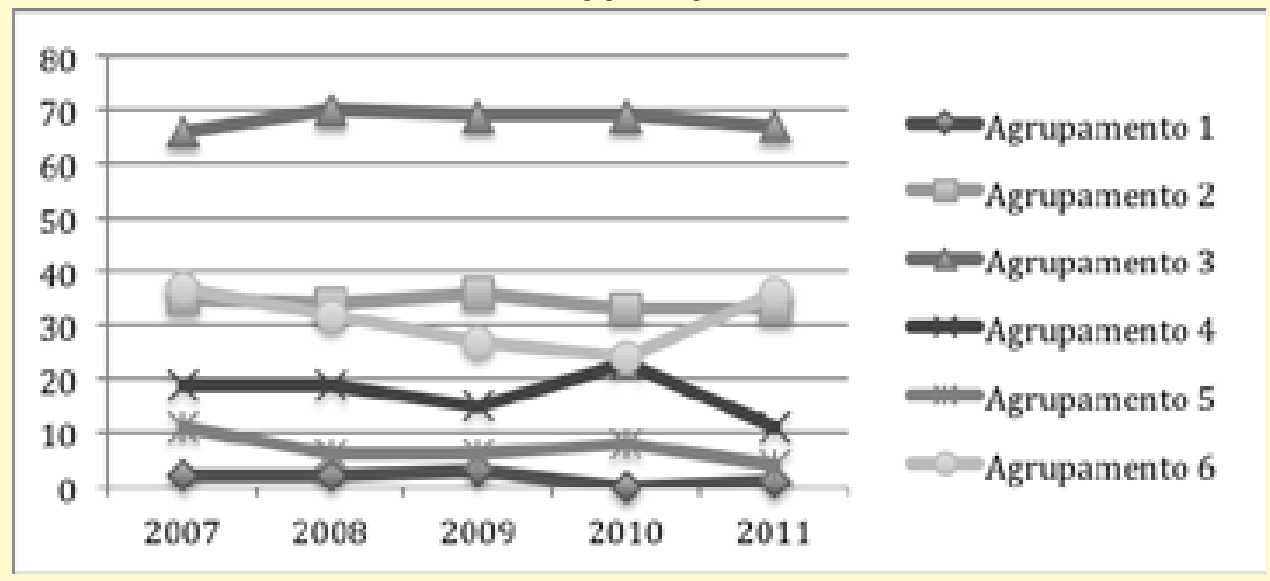

Fonte: Elaborado pela autora.

Como já haviam detectado Nogueira e Lacerda (2014) para a mesma série histórica de 2007-2011, os jovens que procuram o colégio são, em sua maioria, provenientes de famílias nas quais a taxa de conclusão do ensino superior pelo pai variou entre $31 \%$ a $39 \%$, no período, e das mães variou entre $52 \%$ a $58 \%$. Já a porcentagem de pais que não ultrapassaram o ensino médio ficou entre 53 e $62 \%$, e a da mãe variou entre $36 \%$ e $41 \%$. Considerando-se a geração a qual pertencem esses pais, trata-se de famílias com nível de instrução acima dos padrões nacionais e, sobretudo, acima do padrão observado na escola pública em geral. Mas não se pode deixar de observar, em menor proporção, a existência de progenitores com baixa escolaridade cujos filhos poderão conhecer outro destino social aberto pelo acesso a uma escola de qualidade (TORRES, 2014).

Por sua vez, a renda das famílias variou entre 02 a 20 salários mínimos, o que nos permite inferir que a escola abrange um público muito variado, ou seja, um público misto economicamente - tabela 4. Considerando que o ingresso no CAp/COLUNI ocorre por meio de exames, podemos considerar que as principais características dessas famílias são uma atuação ativa na vida escolar dos seus filhos e informações para distinguir e julgar esse estabelecimento escolar. 
Tabela 4: Percentual da renda familiar dos ingressantes de acordo com o número de salários mínimos (em \%) - 2007/2011.

\begin{tabular}{|c|c|c|c|c|c|c|c|c|c|c|c|}
\hline Ano & $\begin{array}{c}\mathrm{n}^{\circ} . \\
\text { absolutos de } \\
\text { ingressantes }\end{array}$ & $\begin{array}{c}\% \\
\text { menos } \\
01\end{array}$ & $\begin{array}{c}\% \\
\text { de } \\
01- \\
02\end{array}$ & $\begin{array}{c}\% \\
\text { de } \\
02- \\
05\end{array}$ & $\begin{array}{c}\% \\
\text { de } \\
05- \\
10\end{array}$ & $\begin{array}{c}\% \% \\
\text { de } \\
10- \\
15\end{array}$ & $\begin{array}{c}\% \\
\text { de } \\
15- \\
20\end{array}$ & $\begin{array}{c}\% \\
\text { de } \\
20- \\
40\end{array}$ & $\begin{array}{l}\% \mathrm{de} \\
40-60\end{array}$ & $\begin{array}{c}\% \\
\text { acima } \\
\text { de } 60\end{array}$ & $\begin{array}{c}\% \\
\text { Total }\end{array}$ \\
\hline 2007 & 170 & 1 & 7 & 31 & 32 & 19 & 6 & 2 & 1 & 1 & 100 \\
\hline 2008 & 163 & 3 & 6 & 31 & 24 & 19 & 10 & 6 & 1 & 0 & 100 \\
\hline 2009 & 156 & 2 & 6 & 32 & 33 & 15 & 4 & 7 & 1 & 0 & 100 \\
\hline & $\begin{array}{c}\mathrm{n}^{\circ} . \\
\text { absolutos de } \\
\text { ingressantes }\end{array}$ & $\begin{array}{c}\% \text { até } \\
01\end{array}$ & $\begin{array}{c}\% \\
\text { de } \\
01- \\
02\end{array}$ & $\begin{array}{c}\% \\
\text { de } \\
02- \\
05\end{array}$ & $\begin{array}{c}\% \\
\text { de } \\
05- \\
07\end{array}$ & $\begin{array}{c}\% \\
\text { de } \\
07- \\
10\end{array}$ & $\begin{array}{c}\% \\
\text { de } \\
10- \\
20\end{array}$ & $\begin{array}{c}\% \\
\text { de } \\
20- \\
30\end{array}$ & $\begin{array}{c}\% \\
\text { acima } \\
30\end{array}$ & & \\
\hline 2010 & 163 & 3 & 11 & 22 & 13 & 23 & 20 & 6 & 2 & $S / I$ & 100 \\
\hline 2011 & 153 & 3 & 11 & 22 & 13 & 23 & 20 & 6 & 2 & $S / I$ & 100 \\
\hline
\end{tabular}

Fonte: Elaborado pela autora.

No que diz respeito aos dados dos alunos, chama a atenção a distribuição dos aprovados segundo o sexo, onde se verifica uma vantagem do sexo masculino - conforme tabela 5.

Tabela 5: Percentual de ingressantes aprovados no exame de seleção segundo o sexo - 2010 e $2011^{15}$.

\begin{tabular}{c|c|c|c|c}
\hline Ano & $\begin{array}{c}\text { Número absoluto de } \\
\text { ingressantes }\end{array}$ & \% Feminino & \% Masculino & \% Total \\
\hline 2010 & 163 & 45,4 & 54,6 & 100 \\
2011 & 153 & 39,2 & 60,8 & 100 \\
\hline
\end{tabular}

Fonte: Elaborado pela autora.

Estaríamos diante de outra ordem nesse espaço escolar específico, segundo a qual os meninos apresentam um resultado superior? Estudos como os de Carvalho (2007) e Weller (2012) destacam que, de modo geral, o sucesso escolar - em praticamente todos os seus indicadores - é mais frequente entre as meninas. Embora, segundo Rosemberg (2001, p. 526), "as instituições sociais podem ser regidas por lógicas não-idênticas; as relações de dominação de classe, raça, gênero e idade podem atuar de modo não-sincrônico na história social de modo geral, de uma instituição em particular, ou na vida da pessoa”. Será necessário, contudo, ampliar nossa reflexão sobre esse ponto, buscando entender esse dado inesperado

15 Foram considerados apenas os anos de 2010 e 2011 porque, nos anos anteriores, o questionário sociocultural não continha esse item. 
e intrigante que coloca o sexo feminino em desvantagem. Uma hipótese inicial seria a de que tanto no exame de ingresso ao colégio bem como em sua grade curricular é dada uma forte ênfase para a área de ciências exatas - como se depreende dos depoimentos dos alunos:

\begin{abstract}
- Eu acho que aqui no Coluni a gente tem uma supervalorização das exatas, sabe, o que é muito tenso. A maioria das Olímpiadas são promovida aqui são de extas, sabe. A gente é muito cobrado em exatas! A gente estuda coisas que as pessoas só estudam na graduação, sabe. A gente entra no $4^{\circ}$ bimestre (da $3^{\circ}$ série) para estudar pré-cálculo. A gente estuda números complexo que não costumam cair no ENEM. A gente estuda muita, muita coisa, a gente é muito cobrado, sabe. E assim, eu falo por mim, o meu gosto pelas humanas ele é abafado a todo momento. Eu tenho que tirar tempo que eu gostaria de estar estudando para humanas e lendo coisas, para estudar para exatas, porque eu só estudo exatas (Lucas, 17 anos, $3^{\mathrm{a}}$ série).
\end{abstract}

Outro dado muito importante acerca do alunado dessa instituição diz respeito a seu passado escolar, em particular a rede de ensino frequentada no nível do ensino fundamental que, no Brasil, funciona como um indicador do pertencimento social. Pois bem, em sua grande maioria, os ingressantes no CAp/COLUNI provêm do sistema privado de ensino - conforme tabela 6.

Tabela 6: Percentual de ingressantes que cursaram no ensino fundamental em instituição pública ou privada - 2007/2011

\begin{tabular}{c|c|c|c|c}
\hline Ano & $\begin{array}{c}\text { Número absoluto de } \\
\text { ingressantes }\end{array}$ & $\begin{array}{c}\text { \% Escola } \\
\text { Pública }\end{array}$ & $\begin{array}{c}\text { \% Escola } \\
\text { privada }\end{array}$ & \% Total \\
\hline 2007 & 170 & 34,7 & 65,3 & 100 \\
2008 & 163 & 33,7 & 66,3 & 100 \\
2009 & 156 & 35,3 & 64,7 & 100 \\
2010 & 163 & 47,9 & 52,1 & 100 \\
2011 & 153 & 44,5 & 55,5 & 100 \\
\hline
\end{tabular}

Fonte: Elaborado pela autora.

Como se vê, o número de aprovados oriundos de escola privada é tradicionalmente bem maior do que aqueles provenientes de escola pública. Há uma variação a partir de 2010, quando o CAP/COLUNI passou a adotar um bônus de $15 \%$ sobre a pontuação final daqueles que cursaram todo o ensino fundamental em escola pública, numa política de ação afirmativa. Some-se a isso, o fato de que as taxas de reprovação no ensino fundamental dos ingressantes no exame de seleção é muito baixa. De um 
A fabricação da excelência na escola pública: notas acerca de práticas educacionais e trajetórias escolares de sucesso

total de 805 aprovados no CAP/COLUNI, de 2007 a 2011, apenas 4, ou seja 0,5\%, tiveram alguma reprovação nesse nível de ensino - tabela 9.

Tabela 9: Distribuição dos ingressantes segundo a reprovação no ensino fundamental - 2007/ 2011

\begin{tabular}{c|c|c|c}
\hline Ano & $\begin{array}{c}\text { Número absoluto } \\
\text { ingressantes }\end{array}$ & $\begin{array}{c}\text { Reprovou uma } \\
\text { vez }\end{array}$ & $\begin{array}{c}\text { Reprovou duas } \\
\text { vezes }\end{array}$ \\
\hline 2007 & 170 & 0 & 0 \\
2008 & 163 & 2 & 0 \\
2009 & 156 & 0 & 1 \\
2010 & 163 & 1 & 0 \\
2011 & 153 & 0 & 0 \\
Total & 805 & 3 & 1 \\
\hline
\end{tabular}

Fonte: Elaborado pela autora.

Temos aqui um indicador de que as trajetórias escolares desses jovens ocorrem sem rupturas e "se caracterizam, de um modo geral, por sua fluência, linearidade, continuidade" (NOGUEIRA, 2000, p. 128). Além disso, já temos pista de que, no decorrer dessas trajetórias, a escolha por esse estabelecimento de ensino se deu de modo precoce, mas, sobretudo, com muita reflexão, sinalizando para uma expressiva aspiração educacional e forte disposição ao investimento escolar - conforme a fala de uma das entrevistadas.

Quando eu estava na $8^{\mathrm{a}}$ série uma professora de ciências falou do COLUNI. [...]. [mas] eu cresci no ensino fundamental pensando no CEFET, porque a minha prima já tinha estudado lá. Aí, eu descobri o COLUNI! Aí, ela [a professora] falou que era uma ótima escola, que tinha em Viçosa, que era dentro da universidade. Aí, eu fiquei animado e fui pesquisar [sobre o colégio]. [...] comecei a pesquisar e vi muitas reportagens, que era o melhor colégio público, que falava que os professores eram com dedicação exclusiva, que eles davam atendimento fora de aula, que tinha projeto de olímpiadas [...]. Eu queria muito vir pra cá (Miguel, 18 anos, $3^{\mathrm{a}}$.série).

\section{Considerações finais}

A excelência escolar e as trajetórias de sucesso são construídas a partir de diferentes variáveis sociais, culturais e econômicas. No caso do CAP/COLUNI, um elemento principal é seu exame de seleção para entrada na instituição, que, por sua vez, requer do/a aluno/a uma série de requisitos implícitos, não verbalizados e práticas escolares 
sobre a maneira de estudar, trabalhar, raciocinar, perguntar, escrever, etc. (MARTíN CRIADO et al., 2000). Sendo assim, diferentemente da representação da má qualidade de escola pública, os ingressantes nessa instituição federal supõem que terão de se esforçar - de acordo com o linguajar dos estudantes -, pois (re)conhecem que essa é uma escola de excelência. Esse reconhecimento é dado tanto pelo exame de seleção do CAP/COLUNI como pela aprovação dos egressos nos concursos de vestibular e no exame do ENEM. A alta aprovação em cursos de alto nível preferidos pelos candidatos permite conjecturar que essa escola tem um efeito na vida dos/as estudantes, tem um valor agregado pela frequência nesse estabelecimento (BRESSOUX, 2011).

Não só a escola, mas também os/as professores/as tem efeito na vida dos estudantes. No CAP/COLUNI há o reconhecimento de que a alta formação dos professores/as tem impacto nas suas formações e nas técnicas de ensino. Como assinala Bressoux (2011), a articulação entre efeitos escola e efeitos sala de aula necessita de mais investigações, pois aquilo que acontece na escola pode influenciar no trabalho dos docentes em sala de aula.

Decerto que nesse processo está em evidência também a individualização e a meritocracia, com uma representação que indica que o esforço e o sacrifício do indivíduo são necessários para o êxito escolar. Esse esforço e sacrifício não são apenas dos/as alunos/as, mas também da escola e da família, pois a educação de qualidade supõe uma série de vantagens futuras para os estudantes e a sociedade. E, sendo uma escola com uma variedade de perfis socioeconômicos, para alguns deles/ as, a única possibilidade de transcender a comunidade familiar e local (FERNANDÉZ ENGUITA, 1997).

Para compreender essa excelência acadêmica consideramos pertinente empregar técnica qualitativas - entrevistas semi-estruturadas - e quantitativas - análise de fontes primárias e secundárias do estabelecimento. Como primeiros resultados, avaliamos que algumas práticas e posições são favoráveis ao trabalho escolar de excelência e acabam por revelar uma atuação positiva da escola na vida desses indivíduos. Entre elas citamos as atividades culturais e os projetos científicos que permitem aos alunos/as tomar parte do espaço escolar. Essa abertura e liberdade dada pela escola também permitem aos estudantes ampliarem sua participação com a criação de outros projetos extraclasses, os quais são aceitos, mas são não organizados pela instituição. 
Outra instância que deve ser considerada é a familiar, a qual elabora projetos educativos para seus filhos e emprega recursos materiais e simbólicos para efetivar suas escolhas. Sabemos que as famílias do CAP/ COLUNI são mistas, o que significa que as ocupações dos pais e das mães são variadas, assim como a média da renda salarial engloba diferentes categorias. De toda forma, essas famílias que cobiçam o CAP/COLUNI reconhecem: as classificações posteriores ao ensino médio, a qualidade da instituição e a capacidade de seus filhos/as, em razão do reconhecimento acadêmico deles no ensino fundamental. Com a concessão do bônus de $15 \%$ para os/as estudantes provenientes do sistema público, essa busca por essa instituição tornou-se ainda mais disputada. Porém, nessa disputa, julgamos que as meninas estão em desvantagem, quando do exame de seleção, pois foi observado que em dois anos consecutivos o número de aprovadas foi menor do que o número de aprovados.

Tentamos aqui demonstrar o encaminhamento que estamos dando a essa pesquisa e os primeiros resultados. Sabemos que ainda temos um caminho a percorrer para compreender as variáveis que constituem a escola de excelência e de seus alunos/as de alto desempenho acadêmico.

\section{Referências}

ARCO NETTO, Nicolau Dela Bandera. Esforço e "vocação": a produção das disposições para o sucesso escolar entre alunos da Escola Técnica Federal de São Paulo. 2011. 251 f. Dissertação (Mestrado) - Universidade de São Paulo. Faculdade de Filosofia, Letras e Ciências Humanas, Programa de Pós-Graduação em Sociologia, São Paulo, 2011.

BARBALHO, Duarte de Magalhães. O colégio de aplicação-CAP/COLUNI da Universidade Federal de Viçosa: histórias de sucesso (Memórias e Identidade). 2008. 163 f. Dissertação (Mestrado em Educação) Universidade Federal de Juiz de Fora, Programa de Pós-Graduação em Educação, Juiz de Fora, 2008.

BRASIL. Decreto-Lei no. 9.053, de 12 de março de 1946. Cria um ginásio de aplicação nas Faculdades de Filosofia do País. Diário Oficial da União, Rio de Janeiro, 12 mar. 1946. Disponível em: < http://www.lexml.gov. br/urn/urn:lex:br:federal:decreto.lei:1946-03-12;9053> Acesso em: 29 fev. 2014.

BRASIL. Lei n 5.692, de 11 de agosto de 1971. Fixa Diretrizes e Bases para o ensino de $1^{\circ}$ e $2^{\circ}$ graus, e dá outras providências. Diário Oficial da União, Brasília, Janeiro, 12 ago. 1971. Disponível em: < http://www. 
planalto.gov.br/ccivil_03/leis/L5692.htm> Acesso em: 29 fev. 2014.

BRASIL. Lei no 4.024, de 20 de dezembro de 1961. Fixa as Diretrizes e Bases da Educação Nacional. Diário Oficial da União, Rio de Janeiro, 27 dez. 1946. Disponível em: < http://www.planalto.gov.br/CCIVIL_03/leis/ L4024.htm> Acesso em: 29 fev. 2014.

BRESSOUX, P. Efeito estabelecimento. In: ZANTEN, Agnès van (Coord.). Dicionário de Educação. Petrópolis, RJ: Vozes, 2011.

CARVALHO, Marília Pinto de. Por que tantos meninos vão mal na escola? Critérios de avaliação escolar segundo o sexo. Trabalho apresentado a $30^{\mathrm{a}}$ reunião da ANPED no GT Sociologia da Educação, Caxambu: ANPED, out./2007.

COLÉGIO DE APLICAÇÃO DA UNIVERSIDADE FEDERAL DE VIÇOSA. Título? Viçosa: UFV, 23 set. 2014. Disponível em: < www.coluni.ufv.br> Acesso em: 29 fev. 2014.

CONFIRA a nota da sua escola no Enem 2012. São Paulo: Educação uol, 26 nov. 2013. Disponível em: < http://educacao.uol.com.br/ infograficos/2013/11/26/confira-a-nota-da-sua-escola-no-enem-2012. htm> Acesso em: 29 fev. 2014.

FERNÁNDEZ ENGUITA, Mariano. La educación en una sociedad en cambio. In: FERNÁNDEZ ENGUITA, Mariano (Coord.). Sociología de las instituciones de educación secundaria. Barcelona: ICE Universitat de Barcelona/HORSORI, 1997.

INSTITUTO NACIONAL DE ESTUDOS E PESQUISAS EDUCACIONAIS ANÍSIO TEIXEIRA. Censo da educação básica: 2012 - resumo técnico. Brasília: INEP, 2013.

MARTÍN CRIADO, Enrique et al. Familias de clase obrera y escuela. Donostia [San Sebastián]: Iralka, 2000.

NOGUEIRA, Maria Alice. A construção da excelência escolar: um estudo de trajetórias feito com estudantes universitários provenientes das camadas médias intelectualizadas. In: NOGUEIRA, Maria Alice; ROMANELLI, Geraldo; ZAGO, Nadir. Família e escola: trajetórias de escolarização em camadas médias e populares. Petrópolis: Vozes, 2000.

NOGUEIRA, Maria Alice; LACERDA, Wania Guimarães. Os rankings de estabelecimentos de ensino médio e as lógicas de ação das escolas: o caso do Colégio de Aplicação da Universidade Federal de Viçosa. KRAWZCYK, Nora (Org.). Sociologia do ensino médio: crítica ao 
economicismo na política educacional. São Paulo: Cortez Editora, 2014.

PONTIFÍCIA UNIVERSIDADE CATÓLICA DE MINAS GERAIS. MINIONU. Belo Horizonte: PUC Minas, 2014. Disponível em: < http://www.ri.pucminas. $\mathrm{br} / \mathrm{minionu} /$ index_atual.php> Acesso em: 01 abr. 2014.

RESENDE, Tânia de Freitas; NOGUEIRA, Cláudio Marques M.; NOGUEIRA, Maria Alice.

Escolha do estabelecimento de ensino e perfis familiares: uma faceta a mais das desigualdades escolares. Educação e Sociedade, Campinas, v. 32, n. 117, p. 953-970, out. / dez. 2011.

ROSEMBERG, Flúvia. Educação formal, mulher e gênero no Brasil contemporâneo. Estudos Feministas, Santa Catarina, v. 2, n. 9, 2001.

TORRES, Leonor Lima. A ritualização da distinção académica. 0 efeito cultura de escola. In:

TORRES, Leonor Lima; PALHARES, José Augusto (Org.). Entre mais e melhor escola em democracia: inclusão e excelência no sistema educativo. Lisboa: Mundos Sociais, 2014.

UNIVERSIDADE FEDERAL DE VIÇOSA. Pró-Reitoria de Ensino. Comissão Permanente de Vestibular e Exames. Exame de Seleção Colégio de Aplicação - COLUNI: $1^{\text {a }}$ série do ensino médio. Viçosa, MG: UFV, 2007, 2008, 2009, 2010, 2011.

UNIVERSIDADE FEDERAL de VIÇOSA. Resolução $n^{\circ}$. 6/2003 - CONSU: baixa o Regimento do Colégio de Aplicação da Universidade de Viçosa _ COLUNI, de 19 de maio de 2003. Disponível em: <http: / /www.ufv.br/ soc/files/pag/consu/completa/2003/03_06.htm>. Acesso em: 01 abr. 2014.

WELLER, W. Juventude e diversidade. Articulando gênero, raça e sexualidade. In:

DAYRELL, Juarez et al. (Org.). Família, escola e juventude: olhares cruzados Brasil-Portugal. Belo Horizonte: Editora UFMG, 2012. 